\title{
A New Species of Mabuya from Tamil Nadu State, Southern India (Squamata: Scincidae)
}

\author{
INDRANEIL DAS \\ Animal Ecology Research Group, Department of Zoology, University of Oxford, \\ South Parks Road, Oxford OXI 3PS, England
}

\begin{abstract}
A new species of Mabuya is described, based on material collected from Kalakkad forest, Tamil Nadu State, southern India. The new species is compared with other previously described species of the genus Mabuya from India.
\end{abstract}

The herpetofauna of the Western Ghats in southwestern India is poorly known (see account of this fauna at a single locality in Inger et al., 1984), and the resurgence of taxonomic work in the past two decades has resulted in the description of several new species of frogs and lizards. While on a herpetological survey to the Kalakkad area of southern Tamil Nadu, a series of three skinks was collected that are being assigned to a new species here:

\section{Mabuya gansi sp. nov.}

Fig. 1

Holotype.-Zoological Survey of India (ZSI) 24826, collected by Indraneil Das on 30 August 1990, from circa $2 \mathrm{~km} \mathrm{NW}$ of Muthalar Road Cross off Sengaltheri-Thalayanai road (towards Moolakasam), Kalakkad Tiger Reserve, Tirunelveli district, Tamil Nadu State, India; adult female. The type-locality is indicated in Fig. 2.

Paratypes. - ZSI 24827 and 24828, same data as holotype.

Diagnosis. - A medium-sized Mabuya distinguished from other members of the genus in possessing the following combination of characters: lower eyelids scaly; supranasals widely separated; prefrontals not in contact with each other; a single pair of nuchals; dorsal scales strongly tricarinate, weakly tricuspid; scales in 30 rows, 41 ventrals, lacking spurs; 14-15 lamellae under the fourth toe and a dark lateral stripe on the body.

Description of Type Series. - Head and neck of equal diameter; snout obtusely pointed; rostral more than twice as high as wide, curving up onto the dorsal surface of head, its posterior margin semicircular; supranasals quadrangular, width less than half length, widely separated from each other; frontonasal longer than broad or as long as broad, meeting the frontals posteriorly; a pair of broad nuchals; nostrils in a single nasal; postnasal present; anterior loreal higher than long, higher than posterior loreal and about half as long; frontoparietals longer than wide, touching the second, third and fourth supraoculars; interparietals longer than wide, separating the parietals; four supraoculars, the second largest; eyelids well developed; lower eyelid with a series of opaque scales; ear openings subcircular, as large as a lateral scale, with three or four short, pointed lobules anteriorly; preorbital length of head exceeding distance between eye and ear opening; temporal scales keeled; five supraciliaries, the first largest, the third longest; six supralabials and six infralabials.

Body fairly robust; body scales without keratinized spur-like structures; dorsal and lateral scales subequal, preanals not enlarged; dorsal and caudal scales weakly tricarinate; scales in 30 rows; middorsal scales with 5-7 strong keels; 41 ventrals between mental and vent; subcaudals not enlarged; well developed pentadactyl limbs; scales on dorsal surfaces of forelimbs with 2 or 3 keels; scales on palm and sole rounded. Hindlimbs reach elbows when adpressed to body; 14-15 lamellae under fourth toe.

Forehead, dorsum of midbody, and tail olive brown, a dark gray brown stripe laterally from the posterior corner of the eye to a little behind the insertion of the hindlimb, covering two scale rows on the trunk; a pale yellow margin above the dark stripe between the ear opening and the area above the forelimb; a pale pink wash on the side of the throat. Ventrally cream.

Etymology. - The new species is named after Professor Carl Gans, in recognition of his contributions to herpetology and for his friendship.

Measurements and Scutellation.-(In $\mathrm{mm}$; holotype followed by paratypes in parentheses): snout-vent length $62.1(62.6,35.9)$; head width $10.2(9.6,5.9)$; total body length $138.0(138,77)$; axilla-groin 37.5 (33.2, 17.9); head to ear opening $13.3(12.8,8.7)$; midbody scale rows $30(30$, $30)$; ventral scales from mental to vent 41 (41, 41); lamellae under fourth toe $15(15,14)$.

Comparisons. - The new species is closely allied to Mabuya allapallensis Schmidt (1926), originally based on a single example from the vi- 

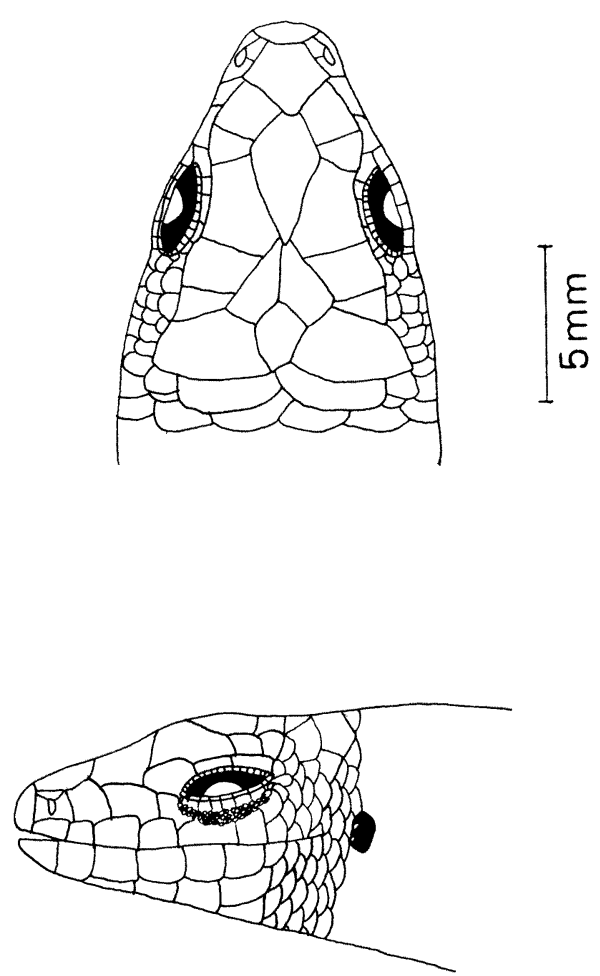

FIG. 1. Mabuya gansi sp. nov. Holotype (ZSI 24826) in dorsal and lateral view.

cinity of Chanda, Madhya Pradesh, in central India; this was synonymized by Smith (1935) under Mabuya macularia. Sharma (1976) showed $M$. allapallensis to be sympatric with $M$. macularia in Goa, and concluded that the two are distinct. Mabuya gansi and $M$. allapallensis share a number of features, such as prefrontal scales widely separated, frontonasals in contact with the nasals, and paired nuchals. Mabuya gansi can be differentiated from $M$. allapallensis in the nature of the temporal scales (keeled in the new species, smooth in M. allapallensis), frontoparietals (separate in the new species but united to form a single large shield in M. allapallensis), and postnasals (present in $M$. gansi, absent in $M$. allapallensis).

In comparison with the other Indian species of Mabuya, M. gansi differs from M. bibroni (Gray), $M$. dissimilis (Hallowell), and M. innotata (Blanford) in possessing scaly lower eyelids (vs. nonscaly eyelids, with a transparent disk in the species mentioned).

Among the valid Indian species of Mabuya possessing scaly lower eyelids, the following features differentiate $M$. gansi: $M$. macularia shows an ear opening smaller than the lateral scales and with a few, indistinct lobules; $M$. carinat $a$ has prefrontals that are in contact, lacks postnasals, and its ear openings are smaller than

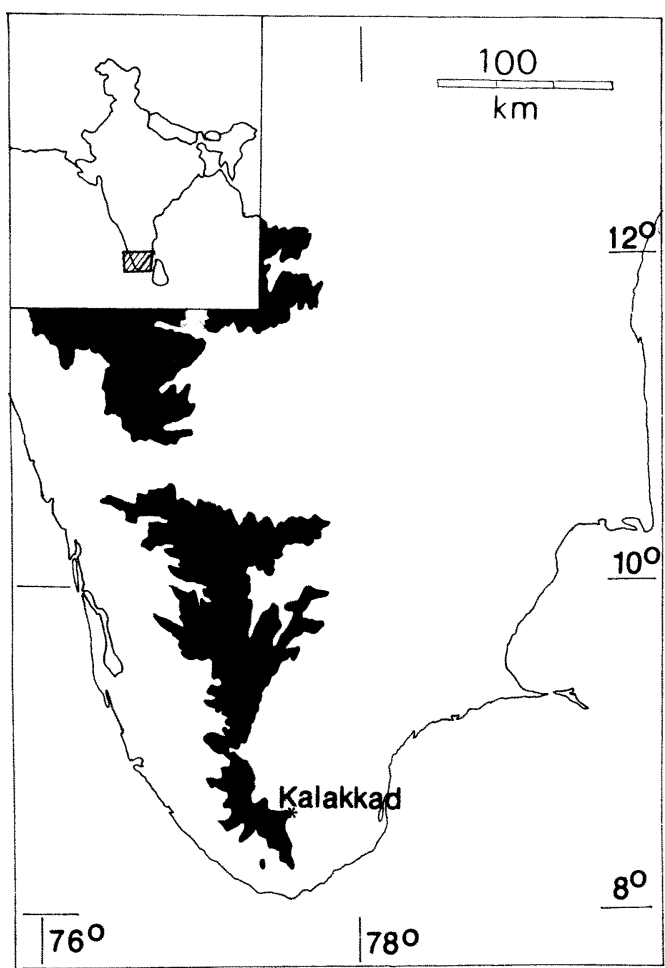

FIG. 2. Southern India, showing the Western Ghats (darkened areas) and the type locality of Mabuya gansi, which lies in the Ashambu Hills, the southern-most range of the Ghats. Shaded area (inset) enlarged below.

the lateral scales; $M$. multifasciat $a$ has 3-5 keeled scales on the dorsum and ear openings smaller than the lateral scales; $M$. tytleri has supranasals that are typically in contact, 24-26 scales around body, and 27-30 lamellae under the fourth toe; $M$. andamanensis has ear openings which are smaller than the lateral scales, and 25-29 lamellae beneath the fourth toe; $M$. rugifera has ear openings that are smaller than the lateral scales, 24-28 scales around the middle of the body, and 22-27 lamellae under the fourth toe; $M$. quadricarinat $a$ has ear openings smaller than the lateral scales, and 26 or 28 scales around the body; $M$. beddomii lacks postnasals, and has $12-$ 15 lamellae beneath the fourth toe; $M$. trivittata lacks postnasals, has 34-36 scales around the body, and 13-14 lamellae under the fourth toe; $M$. rudis shows keeled parietals, a whitish line from the eye to the ear opening, and lacks prominent lobules in the anterior of the ear opening; $M$. clivicola has prefrontals in contact, scales in 28 rows, a narrow dark vertebral stripe, and 46 ventrals; and $M$. nagarjuni has three pairs of nuchals and a square frontonasal.

Ecological Notes. - All examples were collected during midday from leaf litter at the edge 
of a path bordering an evergreen forest. Two of these were obtained from near the base of trees. The holotype had an empty stomach and contained two nearly full-term eggs measuring $12.2 \times 7.4$ and $12.6 \times 7.8 \mathrm{~mm}$. ELI (egg length index: mean egg length/lizard SVL $\times 100$ ) was 19.968. One of the paratypes (SVL $62.6 \mathrm{~mm}$ ) had remains of a cockroach in its stomach, while the other (SVL $35.9 \mathrm{~mm}$ ) had parts of a cricket.

Acknowledgments. -Manuscript preparation was supported by the Madras Crocodile Bank Trust. Aurofilio, Manjula Tiwari, Jennifer Daltry, and Stephan Brown participated in the fieldwork. Carl Gans and Romulus Whitaker read an earlier draft of the manuscript.

\section{LITERATURE Cited}

INGER, R. F., H. B. SHAFFER, M. KOSHY, AND R. BAKDE. 1984. A report on a collection of amphibians and reptiles from Ponmudi, Kerala, South India. J. Bombay Nat. Hist. Soc. 81:406-427, 551-570.

SCHMIDT, K. P. 1926. Amphibians and reptiles of the James Simpson-Roosevelt Asiatic Expedition. Field Mus. Nat. Hist., Zool. Ser. 12:167-173.

SHARMA, R. C. 1976. Records of the reptiles of Goa. Rec. Zool. Surv. India 71:149-167.

SMITH, M. A. 1935. The Fauna of British India, including Ceylon and Burma. Reptilia and Amphibia. Vol. II. Sauria. Taylor and Francis, London. 440 pp.

Accepted: 18 April 1991.

\title{
New Diminutive Eleutherodactylus from the Cordillera Central of Colombia (Amphibia: Leptodactylidae)
}

\author{
JOHN D. LYNCH \\ School of Biological Sciences, The University of Nebraska, Lincoln, Nebraska 68588-0118, USA
}

\begin{abstract}
Three new species of small Eleutherodactylus are named from cloud forests of the northern and central Cordillera Central of Colorado. These species occur at altitudes between 2600 and $3370 \mathrm{~m}$ in Departamentos Antioquia, Caldas, Quindio, and Tolima. The new species apparently are related to $E$. leptolophus and $E$. peraticus that occur at comparable altitudes in the southern portions of the Cordillera Central. A single case of sympatry is known among the five species (between two species in Antioquia).

RESUMEN. - Se describe tres especies nuevas y pequeñas de Eleutherodactylus de los bosques nublados de la parte norte de la cordillera Central de Colombia. Estas especies se encuentra entre 2600 y 3370 m.s.n.m. en los departamentos de Antioquia, Caldas, Quindio, y Tolima. Aparentemente, las especies nuevas tienen parentescos con E. leptolophus y $E$. peraticus de la parte austral de la cordillera Central (en altitudes comparables). Hay un caso de simpatria entre las cinco especies (entre las especies de Antioquia).
\end{abstract}

Although as many as five or six species of diminutive (adults $<30 \mathrm{~mm} \mathrm{SVL}$ ), high-altitude Eleutherodactylus occur in the paramos and high cloud forests on the Nudo de Pasto in southern Colombia (Lynch, 1981, 1984), only three species have been reported from the much larger and topographically more complex Cordillera Central lying to the north of the Nudo de Pasto. Lynch $(1980,1981)$ reported $E$. myersi from the southern part of the Cordillera Central (also western edge of the Nudo de Pasto) and named E. leptolophus and E. peraticus from the paramos de Purace and Las Hermosas, respectively. The apparent scarcity of Eleutherodactylus from the northern Cordillera Central reflected lack of material rather than some biogeographic pattern. Herein, I describe three new species, apparently most closely related to E. leptolophus Lynch, from the middle and northern portions of the Cordillera Central.

When Lynch (1980) described E. leptolophus and $E$. peraticus, he considered them allied to $E$. myersi. Subsequently, Lynch (1984) included $E$. myersi, but not E. leptolophus or E. peraticus, in a group of seven species found in cloud forests and paramos of northern Ecuador and southern Colombia. Eleutherodactylus leptolophus, E. peraticus, and the three new species have larger digital disks than does any species of the southern group (see Lynch, 1980:182). At present, these 